\title{
Captação de recursos no terceiro setor: fatores estratégicos para divulgação de informações
}

Fundraising in the third sector: strategic factors for information disclosure

\section{José Humberto da Cruz Cunha}

Mestre em Ciências Contábeis pela Universidade de Brasília

Professor da Graduação em Ciências Contábeis da Universidade de Brasília

Endereço: Campus Universitário Darcy Ribeiro, Asa Norte, Prédio da Faculdade de

Economia, Administração e contabilidade - FACE/UnB

CEP: 70910-900 - Brasília/ DF - Brasil

E-mail: josehumberto@unb.br

Telefone: (61) 3107-0807

\section{José Matias-Pereira}

Doutor em Ciências Políticas pela Universidade Complutense de Madri - Espanha.

Pós-doutor em Administração pela Universidade de São Paulo - FEA/USP

Professor do Doutorado em Ciências Contábeis da Universidade de Brasília

(UnB/UFPB/UFRN)

Endereço: Campus Universitário Darcy Ribeiro, Asa Norte, Prédio da Faculdade de

Economia, Administração e contabilidade - FACE/UnB

CEP: 70910-900 - Brasília/ DF - Brasil

E-mail: matias@unb.br

Telefone: (61) 3107-0807

Artigo recebido em 07/05/2012. Revisado por pares em 16/08/2012. Reformulado em 15/10/2012. Recomendado para publicação em 31/10/2012 por Sandra Rolim Ensslin (Editora Científica). Publicado em 14/12/2012. 


\title{
Resumo
}

O objetivo presente é verificar até que ponto as informações divulgadas pelas entidades do terceiro setor no Distrito Federal permitem encontrar fatores quanto à Eficiência em alocar recursos aos programas, à Estabilidade Financeira, à quantidade de Informações Disponibilizadas e ao nível de Reputação das organizações sem fins lucrativos, importantes aos doadores segundo Trussel e Parson (2008). A análise fatorial foi utilizada e os resultados corroboram a pesquisa do referencial teórico. Argumentamos, por fim, que os resultados evidenciam uma relação confirmando que quanto menor a Despesa Total proporcional a cada beneficiário há um aumento do grau de eficiência.

Palavras-chave: Terceiro setor. Informações estratégicas. Captação de recursos. Grau de eficiência. Distrito Federal.

\begin{abstract}
The present objective is to verify to what extent the information disseminated by third sector entities in the Federal District allow to find factors regarding the Efficiency in allocating resources to programs, to the Financial Stability, the amount of Information Avialable and the level of Reputation of non-profit organizations, important to the grantors, according to Trussel and Parson (2008). The factorial analysis was used and the results corroborate the theoretical framework research. We argue, finally, that the results evidence a relation confirming that the lower the Total Expense proportional to each beneficiary more increased is the efficiency degree.
\end{abstract}

Keywords: Third sector. Strategical information. Fundraising. Efficiency degree. Federal District.

\section{Introdução}

As informações divulgadas pelas entidades captadoras são fundamentais para sustentar sua continuidade, pois através da prestação de contas, os financiadores das entidades são informados sobre a utilização dos recursos por eles concedidos.

Organizações do terceiro setor buscam a sua continuidade, assim como reza as bases conceituais da contabilidade para todas as entidades. Para sua sobrevivência, buscam recursos no mercado para financiar suas atividades, que podem, por exemplo, ser obtidos por parceiras com instituições de representação internacional que gerenciam fundos multilaterais de investimento ou através de convênios com os Estados e até por entidades também do terceiro setor de outros países. Além das fundações nacionais e empresas nacionais e internacionais como coloca Bettiol Júnior (2005).

Instituições, tais como Banco Mundial (BIRD), Banco Interamericano de Desenvolvimento (BID) e Organização das Nações Unidas (ONU), têm a prática de repassar recursos para financiar projetos sociais (MATIAS-PEREIRA, 2012). A escolha dos projetos e 
das entidades executoras, a serem contempladas com os recursos, é feita a partir de critérios pré-definidos em cada instituição. Além disso, os executores devem prestar contas sobre seus gastos e resultados dos projetos, afinal, os financiadores necessitam de informações para decidir sobre uma nova concessão de recursos.

Da mesma maneira, empresas também repassam recursos - voluntariamente ou por incentivo tributário - às entidades do Terceiro Setor com o intuito de financiar projetos sociais. Entretanto, é possível que haja empresas que escolhem algumas entidades por apresentarem alguns critérios melhores do que outras quanto ao desempenho operacional e ou aspectos financeiros mais sólidos.

Nesse contexto, é perceptível a existência, de um lado, da necessidade em captar recursos por parte das entidades do terceiro setor e, do outro, de instituições com interesse em financiar projetos sociais. Contudo, possuem a necessidade de se comunicar; transmitir informações de um para outro.

O presente trabalho encontra-se no centro desses interesses uma vez que pretende analisar se fatores considerados úteis aos doadores de recursos (TRUSSEL; PARSONS, 2008) podem ser obtidos no âmbito do Distrito Federal, ou seja, verificar se as informações disponíveis ao público são capazes de satisfazer o preenchimento de indicadores úteis para decisões dos doadores.

Assim, o objetivo aqui é verificar até que ponto as informações divulgadas pelas entidades do terceiro setor no Distrito Federal permitem encontrar fatores quanto à Eficiência em alocar recursos aos programas, à Estabilidade Financeira, à quantidade de Informações Disponibilizadas e ao nível de Reputação das organizações sem fins lucrativos.

Tal assunto é discutido na literatura internacional, porém em menor escala na literatura brasileira, assim justifica-se a pesquisa no território brasileiro com esta contribuição a partir de dados das entidades do Distrito Federal. Além disso, os resultados podem ajudar a melhorar o tipo e quantidade de informações divulgadas pelas entidades deste setor em um banco de dados de acesso público.

A presente pesquisa tem essência quantitativa e utiliza a análise fatorial com os dados obtidos em uma fonte pública brasileira e, suas informações possibilitam fazer afirmações a respeito dos quatro fatores divulgados por Trussel e Parsons (2008), corroborando a pesquisa destes com dados da realidade desta região do Distrito Federal e demonstrar ao terceiro setor se os dados por suas respectivas entidades são suficientes para alimentar os indicadores considerados úteis na literatura.

Neste intuito, o trabalho apresenta inicialmente uma contextualização, em seguida demonstra a fundamentação em seu referencial teórico, descrevendo os conceitos dos fatores encontrados por Trussel e Parson (2008) e, logo após apresenta a análise fatorial, seus resultados. Por fim, têm-se as considerações finais e as referências pesquisadas.

\section{Referencial Teórico}

Trussel e Parson (2008) afirmam que fatores como (i) informações sobre a eficiência em alocar recursos, (ii) a estabilidade financeira, (iii) a reputação da organização e (iv) as informações disponibilizadas sobre a missão da entidade e situação dos beneficiários podem afetar o montante de doações recebido pelas entidades sem fins lucrativos estadunidenses, contudo são informações úteis aos doadores. 
De fato, inclusive no Brasil, a literatura considera a existência e utilidade dessas informações. A eficiência em alocar recursos, por exemplo, assim como a eficácia nos resultados são virtudes que serão atribuídas a um terceiro setor de acordo com Falconer (1999). Ainda sobre estas, tais informações sobre as entidades são consideradas como importantes ao se falar de continuidade das organizações desse setor (MILANI FILHO, 2004; FALCONER; VILELA, 2001).

E, segundo Milani Filho (2011), informações capazes de avaliar o desempenho das organizações o terceiro setor é melhor opção do que tradicional superávit contábil, desenvolvido para entidades do mercado; podendo evitar que os doadores alimentem financeiramente entidades menos eficientes operacionalmente.

Adicionalmente, Ribeiro e Timóteo (2012) demonstram que a avaliação de resultados está intimamente ligada à sustentabilidade econômica. Na mesma linha escreve Valadão Jr. et al. (2008), onde em um estudo de caso, portanto demonstrando aplicação prática, deixa claro que não apenas há relação entre a avaliação de resultados e a sustentabilidade econômica, mas também a gestão direcionada a informações seguras e precisas permitem aos gestores a adequada tomada de decisão.

Diante disso, uma vez que os fatores encontrados por Trussel e Parsons (2008) sejam úteis aos doadores de recursos e o resultado dessa pesquisa conhecido, as entidades sem fins lucrativos poderão considerar tais fatores como, ao menos básicos a serem divulgados, sem prejuízo a demais informações úteis. Entretanto são fatores (informações) que podem direcionar a confecção dos relatórios de prestações de contas, caso sejam úteis.

\subsection{Estudo de Trussel e Parsons}

Diversas informações podem ser úteis aos doadores de recursos, principalmente os relatórios financeiros, onde as demonstrações contábeis e outras informações relevantes aos usuários estão inseridas.

Trussel e Parsons (2008) pesquisaram sobre quais informações são úteis e capazes de afetar a decisão de um doador de recursos às entidades sem fins lucrativos. Tal pesquisa foi realizada a partir de dados financeiros suficientes para alimentar alguns indicadores, os quais foram resumidos em quatro fatores capazes de afetar a decisão do doador. Através de análise quantitativa, esse estudo observou uma relação entre dados de algumas contas patrimoniais e de resultado frente ao montante de doações recebidas; sendo todas essas, informações financeiras.

O propósito dessa seção é descrever os conceitos de quatro fatores que afetam a decisão de um doador ao fazer uma concessão de recursos. Os fatores foram pesquisados por Trussel e Parsons (2008) e são: (a) Eficiência; (b) Estabilidade Financeira; (c) Divulgação de Informações; e, (d) Reputação da Entidade.

A pesquisa desses autores reúne diversos estudos anteriores e tem como objetivo sumarizar 14 indicadores, utilizados para avaliação de desempenho operacional das entidades sem fins lucrativos, nos quatro fatores citados que, segundo o estudo, são passíveis de afetar o montante de doações recebidas por essas entidades.

As variáveis analisadas, ou seja, os indicadores do estudo podem ser alimentados com dados encontrados nos relatórios financeiros.

Trussel e Parsons (2008) realizaram uma pesquisa diante da necessidade de saber quais medidas contábeis são úteis aos doadores, usuários das demonstrações financeiras, para 
avaliar as operações das organizações sem fins lucrativos antes de fazer uma doação. $\mathrm{Na}$ revisão de literatura da mencionada pesquisa, os autores verificaram a existência de indicadores que são preenchidos com informações financeiras obtidas nos Demonstrativos Contábeis.

Em suma, verificaram que quatro fatores são capazes de representar tais indicadores. Como conclusão, os autores afirmaram que tais fatores afetam a decisão dos doadores de recursos ao decidir sobre a sua concessão. Os fatores encontrados são a eficiência em alocar recursos aos programas, a estabilidade financeira, o nível de informação disponibilizada aos doadores e a reputação da organização.

\subsection{Eficiência}

Segundo Trussel e Parsons (2004) eficiência refere-se ao grau com que a entidade direciona seus recursos para a missão da organização e esse fator representa os indicadores Preço do Resultado (Price of Output - PRICE), Proporção para Programas (Program Ratio PROG) e Taxa de Custo Administrativo (Administrative Cost Ratio - ADMIN).

Quanto à definição dos indicadores, Weisbord e Domingez (1986 apud TRUSSEL; PARSONS, 2008) acrescentam que o Preço do Resultado (PRICE) é dado pelo custo de um doador comprar um dólar (U\$ 1,00) de resultado para a organização beneficiária, ou outra unidade monetária caso utilize uma moeda distinta do dólar.

Trussel e Parsons (2008) acrescentam ainda que o custo de cada dólar gasto com impostos é maior do que quando gasto com entidade que geram resultados como a caridade. Com essa visão, os doadores doam mais que um dólar, quando comparado com o ato de pagar impostos pelos próprios doadores. Eles sabem que as entidades sem fins lucrativos necessitam de recursos além daqueles destinados exclusivamente aos beneficiários finais para fazer frente aos custos de operacionalização, inclusive os direcionados para outras captações.

Quanto a Taxa Programa (PROG), Baber, Roberts e Visvanathan (2001) esclarecem que esse indicador evidencia o percentual de despesas gastas com programas frente ao total de despesas efetuadas pela entidade. Uma razão considerada por Trussel e Parsons (2008) como o inverso da demonstrada pelo PRICE. Segundo Baber, Roberts e Visvanathan (2001), o PROG é uma medida comumente utilizada para avaliar entidades de caridade. Apesar disso, Trussel e Parsons (2008) desconsideraram esse indicador quando fizeram a análise fatorial justificando que tal medida evidencia a mesma informação que o então utilizado PRICE.

Adicionalmente sobre as despesas direcionadas aos programas, Gordon e Khumawala (1999) relatam que as pessoas quando questionadas sobre a utilidade das informações, elas observam a importância das informações não financeiras, mas dentre as informações financeiras a mais útil considerada é a demonstração de atividades desde que contenha informações das despesas com os programas; podendo ser evidenciadas em percentual pela relação entre essas despesas e o total de despesas da entidade.

Merece destaque, em relação à realidade brasileira o estudo de Milani Filho (2011), que demonstra uma relação entre a Despesa Total e a quantidade de beneficiários (na ocasião estes beneficiários são residentes de Instituições de Longa Permanência para Idosos). Este autor afirma ainda que quanto menor esta relação, ou seja, menos Despesa Total para cada beneficiário, há um aumento do grau de eficiência. 
O outro indicador de eficiência é a Taxa de Custo Administrativo (Administrative Cost ratio - ADMIN) que são as despesas administrativas em percentual sobre o total de despesas da entidade.

De acordo com Trussel e Parsons (2008) há divergência de opiniões em estudos anteriores quanto à utilização desse indicador e citam, por exemplo, que Frumkin e Kim (2001) utilizaram o ADMIN como uma medida de eficiência, mas não encontrou relação deste indicador com as contribuições. Entretanto, cita também que numa outra pesquisa para examinar a relação entre eficiência organizacional e doações, Greenlee e Brown (1999) fizeram uso do mesmo indicador, porém excluindo da sua fórmula das despesas totais, as despesas com angariações.

Apesar de encontrar referências que consideram o ADMIN como medida de estabilidade como é o caso de Tuckman e Chang (1991), citados por de Trussel e Parsons (2008), esses autores encontraram através da análise fatorial que o ADMIN está relacionado à eficiência.

Verificar se a entidade é eficiente é importante, pois conforme sustenta Milani Filho (2011), podem financiar entidades que apresentam superávit financeiro, mas que são caracterizadas como ineficientes economicamente.

\subsection{Estabilidade}

O segundo fator encontrado por Trussel e Parsons (2008) é a estabilidade financeira definida como a habilidade das entidades em continuar suas operações caso se depare com uma redução nos recursos. Nesse contexto, indicadores da estabilidade financeira podem gerar informações que permitam fazer uma análise sobre a continuidade da entidade analisada.

Um indicador da estabilidade financeira é a Adequação do Patrimônio Líquido (Adequacy of Equity - EQUITY). De acordo com Tuckman e Chang's (1991 apud TRUSSEL; PARSONS, 2008) esse indicador é calculado pela razão entre o Ativo Líquido e as Receitas Totais, gerando uma informação sobre o número de períodos de receitas que a entidade sem fins lucrativos tem armazenado.

Dessa maneira, a entidade que possuir maiores ativos líquidos, ou seja, ativo total excluindo suas obrigações com terceiros, provavelmente terá maiores condições para satisfazer necessidades futuras e também obter crédito externo, caso esse seja um critério de avaliação.

Apesar dessa medida (EQUITY) alimentar o doador a respeito da estabilidade financeira da entidade, Trussel e Parsons (2008) afirmam que os doadores não enxergam com "bons olhos" as entidades que não aplicam suas doações nos programas determinados.

Existe nesse ponto um trade-off, que para alguns gestores o EQUITY pode ser um indicador de estabilidade e para outros pode ser um indicador de ineficiência por não aplicar seus recursos nos programas, mas sim acumular riqueza. Entretanto cabe ao doador analisar qual dessas duas questões é prioridade, ou mais útil.

A segunda medida que pode refletir a estabilidade financeira é a Concentração de Receita (Revenue Concentration - CONCEN). O objetivo desse indicador é evidenciar o grau de concentração das receitas quanto às suas fontes. De acordo com Trussel e Parsons (2008), a entidade com uma quantidade menor de fontes de recursos tende a ser mais suscetível a abalos financeiros que uma entidade com o número maior de fontes.

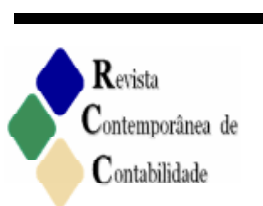

ISSN 2175-8069, UFSC, Florianópolis, v.9, n.18, p.83-102, jul./dez., 2012 
A Concentração de Receita é mensurada, segundo Tuckman e Chang (1991 apud TRUSSEL; PARSONS, 2008) pelo somatório dos quadrados dos percentuais das receitas provenientes de cada fonte específica dividido pelo total de Receitas da entidade, conforme fórmula proposta por Trussel e Parsons (2008) para o cálculo da concentração de receitas.

$$
\text { CONCEN }=\Sigma\left[\left(\frac{\text { Receita_por_Fonte }}{\text { Receita_Total }}\right)\right]^{2}
$$

Caso o numerador da equação seja igual ao denominador, então significa que existe apenas uma fonte de receita. Pelo contrário, o quanto mais fontes existir, então o percentual de cada fonte sobre o total de receitas, elevado ao quadrado e somados ao final, demonstrará o quanto menos a receita está concentrada.

Assim, se existir uma simples fonte de receita o índice será igual a 1 e à medida que aumentar a quantidade de provedores de receitas, o índice tenderá à zero.

A terceira medida é a Margem Operacional (Operating Margin-MARGIN), que pode ser encontrada pela divisão do lucro líquido (receitas menos despesas) pelo total de receitas. É uma medida frente a dificuldades financeiras inesperadas de acordo com Trussel e Parsons (2008), demonstrando o quanto de receitas será armazenado para exercícios posteriores.

\subsection{Disponibilidade de Informação}

O terceiro fator demonstrado por Trussel e Parsons (2008) é a disponibilidade de informações. Segundo esses autores, entidades sem fins lucrativos devem informar potenciais doadores sobre a Missão da Organização e a Situação dos seus Beneficiários, além de fazer propaganda sobre as operações da entidade aos potenciais doadores.

De acordo com Trussel e Parsons (2008) é difícil mensurar diretamente a quantidade de informações recebidas pelos doadores, mas duas proxies para o montante de informações têm sido sugeridas em estudos anteriores utilizados por esses autores.

Da mesma forma que a publicidade utilizada por empresas com finalidades lucrativas transferem informações para potenciais consumidores os esforços de captação de recursos pelas sem fins lucrativos também servem para o mesmo propósito, mas focando para os potenciais doadores.

Com o propósito de mensurar essa informação, Weisbord e Dominguez (1986 apud Trussel; Parsons, 2008) afirmam que o montante de despesas utilizadas para captação de recursos está relacionado diretamente com o total de contribuições recebidas pelas entidades. Assim, o indicador denominado Despesas de Captação (Fundraising Expense - FUND) pode ser um "termômetro" para demonstrar o nível de disponibilidade de informações.

Em seu artigo, Gordon e Khumawala (1999, p. 15) afirmam que se a imagem demonstrada da entidade é positiva, então os custos de captação não são examinados a rigor. Mas, se existem informações negativas pode criar a necessidade por mais informações sobre os custos de captação.

Um segundo indicador para a disponibilidade de informações é a Taxa de Eficiência de Captação (Fundraising Efficiency Ratio - FUNDCONT) que demonstra o percentual de 
despesas de captação sobre as contribuições totais, conforme fórmula proposta por Trussel e Parsons (2008) para o cálculo da taxa de eficiência de captação de recursos.

$$
\text { FUNDCONT }=\frac{\text { Despesas_com_Captaçãoo }}{\text { Contribuiçốes_Totais }}
$$

Comparando com as entidades com fins lucrativos, ao invés da eficiência e eficácia das operações onde pode ser analisado o percentual de despesas operacionais frente às vendas totais, esse indicador fornece informação sobre a eficiência e eficácia da geração atual de contribuições. E, de acordo com Trussel e Parsons (2008), até então não há estudos da área contábil que analisa a relação entre esse indicador e as contribuições.

\subsection{Reputação}

O quarto e último fator demonstrado é a reputação da entidade. Doadores estão mais dispostos a fazer contribuições para organizações que fornecem o melhor serviço (TRUSSEL; PARSONS, 2008). E, a imagem da entidade está diretamente relacionada com a aceitação da qualidade dos serviços. Conseqüentemente, entidades mais conhecidas pelos melhores serviços poderão captar mais recursos.

São quatro os indicadores que podem evidenciar a reputação da entidade. Os que fornecem informações sobre a (1) quantidade de anos de existência, (2) tamanho da entidade, (3) a presença de subvenções governamentais e doações indiretas e (4) o percentual de determinadas receitas sobre as receitas totais.

Quanto ao tempo de existência da entidade (Organization Age - AGE), as organizações mais novas ainda necessitam ganhar espaço e visibilidade, o que outras mais antigas podem já ter solidificado na visão dos doadores.

Além da quantidade de tempo, o tamanho da organização (Organization Size - SIZE) também pode ser um indicativo da reputação. O tamanho é medido pela quantidade de ativos e, de acordo com Tinkelman (1999 apud TRUSSEL; PARSONS, 2004), os doadores visualizam as demonstrações financeiras das entidades menores como sendo menos confiáveis. Subtende que entidades menores têm menos probabilidade de ter conhecimentos sobre alocação de custos e preparação de demonstrações financeiras (TRUSSEL; PARSONS, 2008).

Trussel e Parsons (2008) também mencionam que o crescimento somente é alcançado quando uma entidade é capaz de continuar a gerar receitas ao longo de vários anos. Dessa forma o indicador SIZE pode refletir a capacidade para ser bem sucedida na sua missão e atrair receitas, incluindo as contribuições.

O terceiro indicador é denominado Subvenções Governamentais e Doações Indiretas (Government Grants and Indirect Donations - GRANTS). Esse indicador pode servir como monitor para as entidades sem fins lucrativos, pois a existência de Subvenções Governamentais sujeita as entidades a aumentar o zelo com o controle e divulgação das informações sobre os recursos recebidos, assim como dos resultados alcançados (TRUSSEL; PARSONS, 2008).

Mesmo que os doadores não tenham acesso aos relatórios das entidades sem fins lucrativos, a existência por si só de subvenções governamentais em programas da entidade 
permitem aos doadores aumentarem sua confiança devido à supervisão governamental (TRUSSEL; PARSONS, 2004).

O que não pode necessariamente significar melhora ou mais eficiência nos gastos, pois, segundo achados da pesquisa de Duggan (2000), há evidencias de que hospitais com e sem fins lucrativos, em um momento com redução de aportes governamentais ambos não melhoram os resultados junto aos seus beneficiários. Tal questão é mencionada por Milani Filho (2011).

Milani Filho (2011) expõe também uma análise entre Participação das Transferências Públicas e a eficiência de Instituições de Longa Permanência de Idosos paulistas (filantrópicas) e conclui que não se pode afirmar que aquelas que possuem "maior proporção de recursos públicos no total de receitas obtidas sejam, estatisticamente, menos eficientes do que as organizações que se encontram em situação de menor dependência".

Ainda sobre a reputação, é percebido que as entidades sem fins lucrativos podem cobrar taxas para cobrir os custos dos seus serviços prestados. Assim como, por exemplo, as escolas cobram taxas para manter algum curso de capacitação; até porque e, provavelmente é um tipo de serviço ligado ao objeto social (a atividade principal) dessa entidade (educação). E, o resultado desses serviços depende de um mercado organizado e da qualidade dos produtos.

Dessa forma, de acordo com Trussel e Parsons (2008), a análise do percentual dessas receitas provenientes de uma atividade fim da entidade (Program - PROGREV) separada de outras receitas (Others Revenues - OTHREV), ambos os tipos de receita, comparados em relação às receitas totais podem auxiliar na análise do fator reputação.

A respeito do indicador OTHREV, Weisbrod e Dominguez (1986 apud TRUSSEL; PARSONS, 2004) afirmam que quantidades adicionais de fontes de receita podem dispersar novos doadores, pois esses podem achar que seus recursos serão desnecessários. Entretanto, Trussel e Parsons (2008) evidenciam há uma relação positiva entre fontes alternativas de outras receitas e o reforço da reputação da entidade.

\section{Metodologia da Pesquisa}

Análise Fatorial é uma técnica multivariada que aborda a análise da inter-relação de um número grande de variáveis para definir conjuntos menores capazes de explicar essas variáveis através do agrupamento dessas variáveis pela alta correlação entre elas. É definida por Hair Jr. et al. (1998, p. 90):

Factor analysis is a generic name given to a class of multivatiate statistical methods whose primary purpose is to define the underlying structure in a data matrix. Broadly speaking, it addresses the problem of analyzing the structure of the interrelationships (correlations) among a large number of variables (e.g., test scores, test items, questionnaire responses) by defining a set of common underlying dimensions, known as factors.

Nesse sentido, existe uma redução de dados, onde os fatores passam a explicar as variáveis em maior número. Assim, a sumarização faz a identificação de dimensões basilares ou fatores.

A análise fatorial foi utilizada nessa pesquisa para, assim como Trussel e Parsons (2008), encontrar a quantidade de fatores que possam explicar os indicadores mencionados no 
referencial teórico. Entretanto, diferente de Trussel e Parsons (2008), nessa pesquisa não determinamos uma quantidade de quatro fatores com base na teoria levantada, mas utilizamos o autovalor (eigenvalue), que representa a quantidade de variância representada por um fator.

Dessa maneira, a presente pesquisa buscou identificar se o autovalor traria a mesma quantidade de fatores que mencionada na teoria. Esse fato permite inferir conclusões a respeito da quantidade e tipos de informações disponibilizadas pelas entidades sem fins lucrativos, analisando se essas divulgam informações suficientes para preencher os indicadores (variáveis da análise fatorial) e se os indicadores utilizados são explicados pelos mesmos tipos e quantidade de fatores que a pesquisa de Trussel e Parsons (2008).

\subsection{Dados das Entidades Sem Fins Lucrativos}

É interessante constatar até que ponto as informações divulgadas pelas entidades do terceiro setor no Distrito Federal permitem analisar a eficiência em alocar recursos aos programas, a estabilidade financeira, a quantidade de informações disponibilizadas e nível de reputação das organizações sem fins lucrativos; informações consideradas úteis para Trussel e Parsons (2008).

Com esse intuito, esta pesquisa faz um levantamento de informações divulgadas no cadastro nacional com fins públicos, gerenciado pelo Ministério da Justiça no Brasil, calculando os indicadores fornecidos na pesquisa de Trussel e Parsons (2008) e procedeu à análise fatorial, visando identificar quantos fatores podem resumir os indicadores aqui mencionados com os dados de entidades do Distrito Federal.

O uso da análise fatorial aplicada busca avaliar a correlação existente entre os indicadores, alimentados com dados da realidade, e identificar até que ponto é possível agrupar essas variáveis em fatores de eficiência, estabilidade, quantidade de informações disponibilizadas e reputação.

Quanto ao banco de dados utilizado, o Cadastro Nacional de Entidades de Utilidade Pública (CNEs) "é um sistema eletrônico que tem como principal objetivo facilitar a comunicação entre, Estado, entidades e sociedade, à medida que desburocratiza, padroniza e dá transparência aos processos referentes às qualificações federais" (http://portal.mj.gov.br/data/Pages/MJFC1E6BD5ITEMID9EEAC9CB503B40918DA7222EA6032A1 1PTBRIE.htm. Acesso em 29/03/2012).

A escolha do banco de dados do Ministério da Justiça se deu pela facilidade de acesso e publicidade existente nesse órgão público, inclusive para pesquisadores. Adicionalmente, esse banco de dados eletrônico com acesso público sobre informações de entidades sem fins lucrativos é pioneiro em reunir informações de todas as entidades, as com título de utilidade pública nesse caso, e divulgar na internet.

A busca pelos dados através da internet poderia tornar essa pesquisa inviável devido ao tempo despendido para entrar em entidade por entidade e coletar os dados necessários. Assim, a pesquisa solicitou formalmente ao Ministério da Justiça todos os dados necessários a pesquisa, os quais foram disponibilizados em tempo hábil.

O CNEs possui dados de todas as entidades brasileiras com o título utilidade pública federal. Diante dessa população, apenas as localizadas no Distrito Federal foram obtidas para trabalhar os dados.

Essa escolha deu-se em função da pesquisa ser originada no Distrito Federal (DF) e também porque uma localidade com menos dados facilitava a consulta fornecida pelo

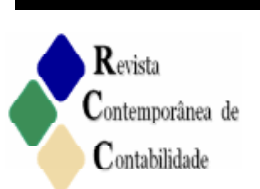


Ministério da Justiça; isso considerando que o DF é o $10^{\circ}$ colocado no ranking de quantidade de entidades registradas nesse cadastro com aproximadamente $2 \%$ de entidades de um total de 12.406 registradas no Brasil.

Quanto aos períodos dos dados, foram disponibilizados os anos de 2007 e 2008. Destes, foi obtida uma amostra de 409 itens, englobando 263 entidades, das quais algumas possuem os dados de ambos os anos e outras apenas de um exercício.

As informações fornecidas para a pesquisa baseou-se naqueles necessários para preencher os indicadores, os quais são representados pelos quatro fatores aqui discutidos.

Os indicadores são preenchidos conforme as fórmulas a seguir, que foram apresentadas por Trussel e Parsons (2008).

Figura 1 - Indicadores utilizados no estudo de Trussel e Parsons (2008)

\begin{tabular}{|c|c|}
\hline Eficiência & $\begin{array}{l}\text { PRICE }=\ln (\text { Despesas Totais/Despesas com Programas }) \\
\text { PROG }=\text { Despesas com Programas } / \text { Despesa Total } \\
\text { ADMIN }=\text { Despesas Administrativas } / \text { Despesa Total }\end{array}$ \\
\hline Estabilidade & $\begin{array}{l}\text { EQUITY }=\text { Ativo Líquido/Receita Total } \\
\text { CONCEN }=\Sigma\left[\left(\frac{\text { Receita_por_Fonte }}{\text { Receita_Total }}\right)\right]^{2} \\
\text { MARGIN }=(\text { Receita Total }- \text { Despesa Total }) / \text { Receita Total }\end{array}$ \\
\hline $\begin{array}{l}\text { Disponibilidade de } \\
\text { Informações }\end{array}$ & $\begin{array}{l}\text { FUND }=\ln (\text { Despesas com Captação }) \\
\text { FUNDCONT }=\text { Despesas com Captação/Contribuições Totais }\end{array}$ \\
\hline Reputação & $\begin{array}{l}\text { AGE }=\ln \left(n^{\circ} \text { de anos de existência a partir da isenção tributária) }\right. \\
\text { SIZE }=\ln (\text { Ativo Total) } \\
\text { GRANTS }=\ln \text { (Auxílio Governamental+Contribuições Indiretas) } \\
\text { PROGREV }=\ln \text { (Receita de Programas) } \\
\text { OTHREV }=\ln \text { (Receita Total }- \text { Contribuições Diretas - Contribuições Indiretas - } \\
\quad \text { Auxílio Governamental }- \text { Receita de Programas) }\end{array}$ \\
\hline
\end{tabular}

Fonte: Trussel e Parsons (2008, p.267, tradução nossa).

Assim como observado, todos os dados necessários são financeiros e são passíveis de serem encontrados nas Demonstrações Contábeis. Nesse sentido, o Plano de Contas com dados do Balanço Patrimonial e da Demonstração de Resultado do Exercício foi analisado com a finalidade de segregar as contas que preencham os indicadores. Esse plano de contas é padrão para todas as cadastradas no CNEs.

Ao todo são 22.811 linhas com dados das Demonstrações Contábeis das 263 entidades, onde 146 possuem dados de ambos os anos, 93 apenas de 2007 e 24 apenas de 2008. Assim, os indicadores foram calculados conforme disponibilização dos dados no período mencionado, totalizando 3.152 itens calculados ("Qtd. itens calculados") para os indicadores apresentados no quadro a seguir. Este banco de dados é de acesso público. O Banco de Dados público do $\mathrm{CNE}$ pode ser acessado em: http://portal.mj.gov.br/data/Pages/MJFC1E6BD5ITEMID1C837A412B2B430F8F9C1FF0CB7341FF PTBRIE.htm. 


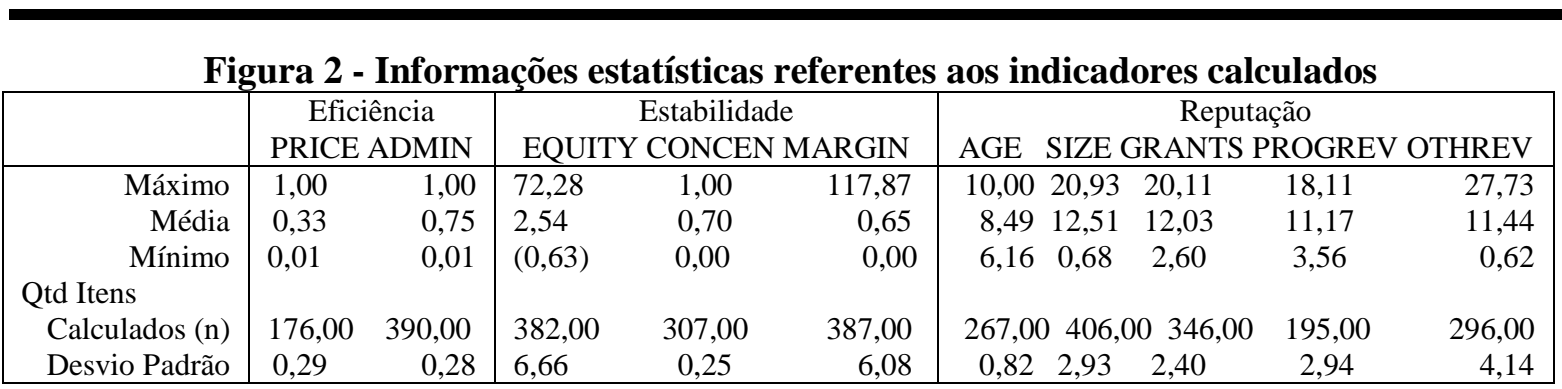

Fonte: Elaboração própria.

Para calcular o indicador PRICE é necessário selecionar as despesas com os programas, ou seja, as destinadas aos seus beneficiários, as que são direcionadas a finalidade social da entidade.

Diante da análise do plano de contas, as seguintes contas foram selecionadas como Despesas com Programas.

Figura 3 - Resumo das contas de despesas utilizadas como específicas dos programas

\begin{tabular}{|ll|}
\hline Demonstrativo & Descrição \\
\hline DESPESA - CUSTOS DE PROJETOS & Custos de Projetos \\
DESPESA - DESPESAS BENEFICENTES & Doação de Alimentos \\
DESPESA - DESPESAS COM BOLSAS DE ESTUDOS A TERCEIROS & Curso Superior \\
RECEITA - DEDUÇÕES DAS RECEITAS & $(-)$ Atendimento gratuito \\
& $(-)$ Bolsas de estudo concedidas \\
\hline
\end{tabular}

Fonte: Elaboração própria.

As informações da receita por captação, indispensáveis para preencher o indicador CONCEN, foi encontrada a partir de uma informação adicional às demonstrações contábeis, o percentual de cada fonte de recursos para cada entidade. A partir de então esse percentual foi aplicado ao total da receita, entidade por entidade.

Os dados quanto aos anos de existência das entidades deve ser iniciada a partir da suposta data em que obteve a isenção tributária. Não sendo possível obter esse tipo de dados de maneira precisa, consideramos então a data de obtenção do Título de Utilidade Pública Federal, que é um requisito para solicitar a isenção junto aos demais órgãos do governo.

Segundo Trussel e Parsons (2008, p.272), as Receitas com Programas são consideradas aquelas provenientes de seus serviços.

Uma exceção quanto aos dados obtidos são os necessários para preencher os indicadores de Disponibilidade de Informações, os quais dependem das Despesas com Captação, aquelas direcionadas a captação de recursos, como propagandas, angariações etc.; as destinadas a obter recursos. A falta desses dados prejudica a análise desse indicador.

Diante dos indicadores calculados, a análise multivariada foi realizada.

\section{Apresentação e Discussão dos Resultados}

Inicialmente, é indispensável destacar que Trussel e Parsons (2008) não utilizaram o indicador PROG, pois o mesmo representa a anti-imagem de PRICE com seu coeficiente de correlação anti-imagem superior a 0,90. Em função disso, também foi descartado dessa pesquisa, com o intuito de estudar os mesmos indicadores testados estatisticamente por esses autores. 
Uma limitação observada é a falta de dados que preencham todos os indicadores dos diferentes fatores para todas as entidades em análise. Dessa maneira, foi efetuada a análise fatorial apenas com as entidades e para os anos que possuíssem dados suficientes para preencher todos os dez indicadores da análise.

Além disso, não obtivemos dados para calcular os indicadores de Divulgação de Informações. A falta dessa informação pode ser atribuída à falta de campo específico, nas Demonstrações Financeiras padronizadas pelo Ministério da Justiça, para informar o montante de despesas direcionadas à captação de recursos.

Diante dessas considerações, é possível iniciar o procedimento para encontrar os fatores. O primeiro passo foi analisar se os dados iniciais viabilizam a utilização da AF (análise fatorial) de forma satisfatória. Etapa em que se analisa o grau de relacionamento entre as variáveis e a conveniência da aplicação da Análise Fatorial, a medida de adequação da amostragem e a esfericidade (CORRAR et al., 2009).

A existência de correlação entre os indicadores é um pressuposto da análise fatorial (CORRAR et al., 2009). Entretanto se todas as variáveis foram inteiramente correlacionadas entre si, provavelmente existirá um fator que as explica, pois a alta correlação é fundamental para o agrupamento em fatores.

Segundo Corrar et al., (2009, p.100) um valor mínimo para ser observado na Matriz de Correlação é 0,40. Na correlação entre as variáveis aqui analisadas, os indicadores EQUITY, CONCEN e MARGIN não possuem correlação acima de 0,40 com pelo menos um dos demais indicadores.

De maneira complementar à análise de correlação, a análise do Kaiser-Meyer-Olkin Measure of Sampling Adequacy é uma medida de adequação da amostra. Com esse teste é possível observar o grau de explicação dos dados a partir dos fatores encontrados na análise fatorial.

De acordo com Corrar et al., (2009, p.100) o número resultado desse teste não deve ser inferior a 0,500 , pois significaria que os fatores encontrados na análise não conseguem descrever as variações dos dados originais de maneira satisfatória.

Após o processamento dos dados nessa pesquisa, conforme a tabela a seguir, o indicador encontrado é 0,567 ; maior que 0,500 .

Tabela 1 - Teste de Adequação da Amostra e de Esfericidade

\begin{tabular}{llr}
\hline \multicolumn{3}{c}{ KMO and Bartlett's Test } \\
\hline Kaiser-Meyer-Olkin Measure of Sampling Adequacy. & 0,567 \\
Bartlett's Test of Sphericity & Approx. Chi- & 423,452 \\
& Square & 45 \\
& Df & 0,000 \\
\hline
\end{tabular}

Fonte: Dados da pesquisa a partir do SPSS 17.0.

Além desse teste, outro para indicar se existe relação suficiente entre os indicadores da análise fatorial (CORRAR et al., 2009, p.102) é o teste de Bartlett's de Esfericidade, onde deve ser observada sua significância, não devendo ultrapassar 0,05 ou chegar a 0,10 para não inviabilizar a capacidade dos fatores em explicar os indicadores.

Como demonstrado, o valor de significância para o teste de esfericidade de Bartlett's foi 0,000 , valor que aumenta o poder de explicação dos fatores extraídos na análise. 
O Bartlett teste proporciona a probabilidade estatística da Matriz de Correlação ter correlações significantes entre as variáveis (HAIR JR. et al., 1998, p99). Isso significa dizer que o resultado desse teste encontrado aqui na pesquisa $(\operatorname{Sig} .=0,000)$ demonstra haver correlação estatisticamente significativa entre os indicadores, o que reforça o poder de explicação dos fatores sobre as variáveis utilizadas.

O passo seguinte foi analisar Matriz Anti-imagem, que seus valores na diagonal da correlação anti-imagem indicam as medidas de adequação da amostragem (Measure of Sampling Adequacy) de cada indicador analisado. Os valores da diagonal são ordenados a seguir:

Tabela 2 - Resultado diagonal das correlações da Matriz Anti-Imagem

\begin{tabular}{lcll}
\hline \multicolumn{4}{c}{ Anti-image Correlation } \\
\hline PRICE &, $443^{\mathrm{a}}$ & AGE &, $760 \mathrm{a}$ \\
ADMIN &, $484^{\mathrm{a}}$ & SIZE &, $609 \mathrm{a}$ \\
EQUITY &, $218^{\mathrm{a}}$ & GRANTS &, $606 \mathrm{a}$ \\
CONCEN &, $509^{\mathrm{a}}$ & PROGREV &, $613 \mathrm{a}$ \\
MARGIN &, $619^{\mathrm{a}}$ & OTHREV &, $748 \mathrm{a}$ \\
\hline \multicolumn{2}{l}{ a. Measures of Sampling Adequacy(MSA) } \\
Fonte: Dados da pesquisa a partir do SPSS 17.0.
\end{tabular}

De acordo com Corrar et al. (2009), os valores inferiores a 0,50 são considerados muito pequenos para análise. É o que acontece com o indicador EQUITY $(0,218)$, PRICE $(0,443)$ e ADMIN $(0,484)$.

A Matriz Anti-imagem indica o grau de explicação dos fatores para cada variável de forma individual (HAIR JR. et al., 1998; CORRAR et al., 2009). Assim verificamos que o valor correspondente a EQUITY $(0,218)$ é pequeno. Significa dizer que um dos fatores encontrado pode não representá-lo significativamente.

Adicionalmente às observações dos testes iniciais, verificamos a comunalidade que demonstra o grau de explicação individual de cada indicador pelos seus fatores (MORAES; ABIKO, 2006).

Tabela 3 - Resultado do teste de comunalidades

\begin{tabular}{lcclcc}
\hline \multicolumn{7}{c}{ Communalities } \\
\hline & Initial & Extraction & Initial & Extraction \\
PRICE & 1,000 &, 871 & AGE & 1,000 &, 553 \\
ADMIN & 1,000 &, 820 & SIZE & 1,000 &, 868 \\
EQUITY & 1,000 &, 638 & GRANTS & 1,000 &, 611 \\
CONCEN & 1,000 &, 384 & PROGREV & 1,000 &, 903 \\
MARGIN & 1,000 &, 362 & OTHREV & 1,000 &, 631 \\
\hline Extraction Method: Principal Component Analysis. & & & \\
\hline Fonte: Dados da pesquisa a partir do SPSS & 17.0.
\end{tabular}

As informações obtidas pela análise não rotacionada (antes da varimax) apresentaram uma capacidade de explicação das variâncias pelos fatores de $66,41 \%$. Isso pode ser observado na tabela a seguir demonstrando a Variância Total Explicada: 
Captação de recursos no terceiro setor: fatores estratégicos para divulgação de informações

Tabela 4 - Demonstrativo de variância total explicada pelos fatores da análise

\begin{tabular}{|c|c|c|c|c|c|c|c|c|c|}
\hline \multicolumn{10}{|c|}{ Total Variance Explained } \\
\hline \multirow[b]{2}{*}{ Component } & \multicolumn{3}{|c|}{ Initial Eigenvalues } & \multicolumn{3}{|c|}{$\begin{array}{c}\text { Extraction Sums of Squared } \\
\text { Loadings } \\
\end{array}$} & \multicolumn{3}{|c|}{$\begin{array}{l}\text { Rotation Sums of Squared } \\
\text { Loadings }\end{array}$} \\
\hline & Total & $\begin{array}{c}\% \text { of } \\
\text { Variance }\end{array}$ & $\begin{array}{c}\text { Cumulative } \\
\%\end{array}$ & Total & $\begin{array}{l}\% \text { of } \\
\text { Variance }\end{array}$ & $\begin{array}{c}\text { Cumulative } \\
\%\end{array}$ & Total & $\begin{array}{c}\% \text { of } \\
\text { Variance }\end{array}$ & $\begin{array}{c}\text { Cumulative } \\
\%\end{array}$ \\
\hline 1 & 3,346 & 33,457 & 33,457 & 3,346 & 33,457 & 33,457 & 3,085 & 30,846 & 30,846 \\
\hline 2 & 1,770 & 17,702 & 51,159 & 1,770 & 17,702 & 51,159 & 1,977 & 19,775 & 50,621 \\
\hline 3 & 1,525 & 15,253 & 66,412 & 1,525 & 15,253 & 66,412 & 1,579 & 15,791 & 66,412 \\
\hline 4 & 898 & 8,975 & 75,387 & & & & & & \\
\hline 5 & 851 & 8,506 & 83,893 & & & & & & \\
\hline 6 & ,646 & 6,460 & 90,353 & & & & & & \\
\hline 7 & ,422 & 4,221 & 94,574 & & & & & & \\
\hline 8 & ,366 & 3,661 & 98,235 & & & & & & \\
\hline 9 & , 120 & 1,205 & 99,440 & & & & & & \\
\hline 10 & 056 & ,560 & 100,000 & & & & & & \\
\hline
\end{tabular}

Fonte: Dados da pesquisa a partir do SPSS 17.0.

Considerando os baixos valores de correlação e anti-imagem de EQUITY e o valor abaixo de 0,60 com o teste Kaiser-Meyer-Olkin Measure of Sampling Adequacy, ficou decidido rodar novamente a análise, porém sem presença de EQUITY, pois segundo Hair Jr. et al. (1998, p.99), até 0,60 não é conveniente efetuar a análise fatorial.

Em função da retirada do indicador EQUITY, novos valores são assumidos para os testes iniciais conforme demonstrado a seguir:

Tabela 5 - Novo teste de Adequação da Amostra e de Esfericidade, excluindo um indicador KMO and Bartlett's Test

\begin{tabular}{llr}
\hline Kaiser-Meyer-Olkin Measure of Sampling Adequacy. &, 616 \\
Bartlett's Test of Sphericity & Approx. Chi-Square & 361,011 \\
& Df & 36 \\
& Sig. &, 000 \\
\hline Fonte: Dados da pesquisa a partir do SPSS & 17.0. &
\end{tabular}

Tabela 6 - Resultado do novo teste de comunalidades, excluindo um indicador

\begin{tabular}{lcclccccc}
\hline \multicolumn{7}{c}{ Communalities } \\
\hline & Initial & Extraction & \multicolumn{1}{c}{ Initial } & Extraction & Initial & Extraction \\
PRICE & 1,000 &, 874 & AGE & 1,000 &, 549 & OTHREV & 1,000 &, 634 \\
ADMIN & 1,000 &, 784 & SIZE & 1,000 &, 866 & & & \\
CONCEN & 1,000 &, 661 & GRANTS & 1,000 &, 573 & & & \\
MARGIN & 1,000 &, 484 & PROGREV & 1,000 &, 891 & & & \\
\hline
\end{tabular}

Fonte: Dados da pesquisa a partir do SPSS 17.0.

Assim, o grau de explicação dos fatores sobre as variáveis ficou acima de 0,60 , obtido pelo Kaiser-Meyer-Olkin Measure of Sampling Adequacy. E, os valores de comunalidade em geral são mantidos acima de 0,50, exceto quanto ao indicador MARGIN $(0,484)$. Além disso, a nova Matriz Anti-imagem foi obtida com suas principais correlações demonstradas a seguir: 
Tabela 7 - Resultado diagonal das correlações da Matriz Anti-Imagem, após a exclusão de um indicador

\begin{tabular}{llllll}
\hline \multicolumn{5}{c}{ Anti-image Correlation } \\
\hline PRICE &, $404^{\mathrm{a}}$ & AGE &, $715^{\mathrm{a}}$ & OTHREV &, $759^{\mathrm{a}}$ \\
ADMIN &, $507^{\mathrm{a}}$ & SIZE &, $764^{\mathrm{a}}$ & & \\
CONCEN &, $477^{\mathrm{a}}$ & GRANTS &, $640^{\mathrm{a}}$ & \\
MARGIN &, $604^{\mathrm{a}}$ & PROGREV &, $611^{\mathrm{a}}$ & \\
\multicolumn{5}{l}{ a. Measures of Sampling Adequacy(MSA) } \\
Fonte: Dados da pesquisa a partir do SPSS & & \\
\hline
\end{tabular}

Nesse caso, apenas o PRICE e CONCEN estão com o valor abaixo do menor valor sugerido por Corrar et al. (2009); inferiores a 0,50 são considerados muito pequenos para análise.

Entretanto após as novas análises iniciais, foi decido prosseguir com a análise fatorial, pois no geral, os resultados dos testes demonstram que os fatores poderão representar os indicadores de maneira satisfatória.

Em seguida foi utilizada a rotação ortogonal varimax (HAIR JR. et al., 1998). Essa rotação minimiza a ocorrência de uma variável possuir altas cargas fatoriais para diferentes fatores, permitindo que uma variável seja facilmente identificada com um único fator (CORRAR et al., 2009, p.89). Assim, são encontrados três fatores:

\begin{tabular}{|c|c|c|c|}
\hline \multicolumn{4}{|c|}{ Component Matrix ${ }^{\mathrm{a}}$} \\
\hline & \multicolumn{3}{|c|}{ Component } \\
\hline & 1-Reputação & $\begin{array}{c}2- \\
\text { Eficiência } \\
\end{array}$ & 3-Estabilidade \\
\hline PRICE & ,458 & $\underline{-, 809}$ & ,098 \\
\hline ADMIN &,- 383 &, 747 &,- 281 \\
\hline CONCEN & , 193 &, 389 &, 687 \\
\hline MARGIN & 199 & ,048 &, 665 \\
\hline AGE &, 579 & ,456 &,- 083 \\
\hline SIZE & $\underline{\mathbf{8 8 0}}$ & ,293 &,- 074 \\
\hline GRANTS &,$\underline{612}$ &,- 075 &,- 439 \\
\hline PROGREV &, 934 &,- 120 &,- 062 \\
\hline OTHREV &, 744 & ,281 & ,030 \\
\hline
\end{tabular}

Extraction Method: Principal Component Analysis.

a. 3 components extracted.

Fonte: Dados da pesquisa a partir do SPSS 17.0.

A análise das informações produzidas pela varimax evidencia um resultado interessante, os indicadores são agrupados nos mesmos fatores que a pesquisa de Trussel e Parsons (2008).

Registre-se que, AGE, SIZE, GRANTS, PROGREV e OTHREV são representados pelo mesmo fator, que a literatura classifica como Reputação. Os indicadores PRICE e ADMIN são explicados por outro fator, denominado Eficiência e o CONCEN e MARGIN pelo terceiro, chamado Estabilidade. 
Considerando que nenhuma instituição do banco de dados analisado possuía dados suficientes para preencher os indicadores FUND e FUNDCONT, correspondente ao fator Disponibilidade de Informações, não faz sentido a existência de um quarto fator, o que foi demonstrado estatisticamente com a aplicação da análise fatorial com autovalor e não com a quantidade de fatores determinada pelo pesquisador.

Ao observar a matriz com os fatores, é verificado que o PRICE (PRICE=ln[despesa total/despesa com programas]) possui sinal negativo sugerindo que despesas não direcionadas aos programas significam baixa eficiência.

O sinal positivo em ADMIN demonstra justamente o inverso do que ocorre com PRICE, que está inversamente proporcional ao fator. Ou seja, menores gastos com despesas administrativas e maiores direcionadas aos programas representam maior eficiência.

Adicionalmente, o ADMIN apresenta um sinal negativo nos demais fatores, indicando que um ADMIN elevado representa baixa Reputação e desfavorável Estabilidade financeira.

Diante do exposto, ainda resta verificar se a amostra dos dados, composta pelas entidades do Distrito Federal corresponde a um conjunto apenas, que no geral pode-se dizer que é um grupo de entidades que não prestam contas.

Sendo assim temos a seguinte hipótese: $\mathrm{H} 0=$ A quantidade de entidades que divulga as informações sobre a eficiência em alocar recursos, a estabilidade financeira, a reputação da organização e informações disponibilizadas sobre a missão da entidade e situação dos beneficiários é igual a quantidade das que não divulgam (H0: $\boldsymbol{p}$ divulga $=\boldsymbol{p}$ não divulga) e Hipótese Alternativa (H1: pdivulga $\neq$ pnão divulga)

Se a hipótese nula for aceita, subentende-se que a quantidade de não divulgação não permite afirmar estatisticamente que as entidades de fato não divulgam suas informações. $\mathrm{E}$, caso seja rejeitada, é possível afirmar, em conjunto com análise da freqüência, que existe diferenças estatística entre as que divulgam das que não divulgam.

Para realização dessa análise foi utilizado o qui-quadrado a fim de avaliar se existe significância estatística para afirmar que as informações para preencher todos os indicadores não são divulgadas.

Antes de realizar esse teste, consideramos os que não divulgam todas as informações como 1 e os fornecem 2. Observe-se que a presente pesquisa identificou que as entidades brasileiras sem fins lucrativos não divulgam informações segregadas das despesas com captação, assim os indicadores do fator Disponibilidade de Informações não foram preenchidos. Ao testar essa hipótese nula temos 230 entidades do Distrito Federal que não divulgam e outras 52 que divulgam as informações suficientes para preencher todos os indicadores mencionados nessa pesquisa.

Englobando todas as 230 entidades, algumas com dados de 2007 e ou 2008, temos uma amostra de 409 itens a serem analisados, divididos conforme a tabela a seguir:

Tabela 9 - Frequência da quantidade de entidades que divulgam informações suficientes para preencher os indicadores versus a quantidade das que não divulgam

\begin{tabular}{lccc}
\hline \multicolumn{4}{c}{ Informações Divulgadas } \\
\hline & Observed N Expected N & Residual \\
1 - Não divulgam & 325 & 204,5 & 120,5 \\
2 - Divulgam & 84 & 204,5 & $-120,5$ \\
Total & 409 & & \\
\hline Fonte: Dados da pesquisa a partir do SPSS 17.0.
\end{tabular}

Fonte: Dados da pesquisa a partir do SPSS 17.0. 
Ao analisar o $p$-value menor que 0,05 e o qui-quadrado acima do $X^{2}$ tabelado $(3,841)$ é observado que existe evidência estatística para rejeitar a hipótese nula, assim os dois grupos não são significativamente iguais e então, não é possível afirmar estatisticamente que as entidades, de um modo em geral, divulgam as informações consideradas úteis, pois a amostra das que não divulgam são significativamente distinta e maior.

Tabela 10 - Qui-quadrado sobre a frequência da quantidade de entidades que divulgam informações suficientes para preencher os indicadores versus a quantidade das que não divulgam

\section{Test Statistics}

\begin{tabular}{lr}
\multicolumn{2}{c}{ Test Statistics } \\
\hline Chi-Square & Informações Divulgadas \\
Df &, 000 \\
Asymp. Sig. & $142,007^{\text {a }}$ \\
\hline a. 0 cells (,0\%) have expected frequencies less than 5. The minimum expected cell frequency is 204,5. \\
Fonte: Dados da pesquisa a partir do SPSS 17.0.
\end{tabular}

\section{Conclusão}

Observa-se, conforme destacado neste estudo, que na literatura internacional Trussel e Parson (2008), encontraram quatro fatores úteis aos doadores de recursos, resumindo 14 indicadores: (a) Eficiência; (b) Estabilidade Financeira; (c) Divulgação de Informações; e, (d) Reputação da Entidade.

Diante do objetivo proposto de verificar até que ponto as informações divulgadas pelas entidades do terceiro setor no Distrito Federal permitem encontrar estes fatores é possível afirmar que não há informações suficientemente divulgadas por tais entidades neste banco de dados que permita levantar os indicadores responsáveis pelo fator "Disponibilidade de Informações".

Este estudo também demonstra que, estatisticamente, a maior parte das entidades do Terceiro Setor do Distrito Federal não divulga informações suficientes para preencher os indicadores aqui estudados através do banco de dados público do Cadastro Nacional de Entidades de Utilidade Pública, prejudicando a comparação de informações por parte dos doadores.

Outro achado durante a pesquisa é que ao observar a matriz com os fatores, verificouse que o PRICE (PRICE=ln[despesa total/despesa com programas]) possui sinal negativo indicando assim que despesas não direcionadas aos programas significam baixa eficiência. $\mathrm{E}$, o sinal positivo em ADMIN, demonstrando justamente o inverso do que ocorre com PRICE, e ambos os resultados permitem inferir que menores gastos com despesas administrativas e maiores direcionadas aos programas representam maior eficiência. Adicionalmente, o ADMIN apresenta um sinal negativo nos demais fatores, indicando que um ADMIN elevado representa baixa Reputação e desfavorável Estabilidade financeira.

Destacamos, por fim, que estes resultados estão alinhados ao demonstrado por Milani Filho (2011), onde fica evidente uma relação entre a Despesa Total e a quantidade de 
beneficiários, o que nos permite afirmar que quanto menor a Despesa Total na proporção para cada beneficiário há um aumento do grau de eficiência.

Este trabalho, que buscou contribuir para ampliar o nível de conhecimento no tema objeto do estudo no âmbito do Distrito Federal, nos permite sugerir que em trabalhos futuros, sejam testados os dados de outros anos e de outros estados brasileiros.

\section{Referências}

BABER, Willian R.; ROBERTS, Andrea A.; VISVANATHAN, Gnanakumar. Charitable Organizations' Strategies and Program-Spending Ratios. American Accounting Association: Accounting Horizons, v. 15 n. 4. dec., p. 329-343, 2001.

BETTIOL JUNIOR, Alcides. Formação e Destinação do Resultado em Entidades do Terceiro Setor: um Estudo de Caso. 2005. Dissertação (Mestrado). Curso de PósGraduação Controladoria e Contabilidade, Universidade de São Paulo - FEA/USP, São Paulo, 2005.

CORRAR, Luiz J.; PAULO, Edilson; DIAS FILHO, José Maria (coordenadores). Análise Multivariada: para os cursos de administração, ciências contábeis e economia. São Paulo: Atlas, 2009.

FALCONER, Andrés P.. A Promessa do Terceiro Setor: um Estudo sobre a Construção do Papel das Organizações Sem Fins Lucrativos e do seu Campo de Gestão. São Paulo: USP, 1999.

FALCONER, Andrés P.;VILELA, Roberto. Recursos Privados para Fins Públicos: As Grantmakers Brasileiras. São Paulo: Fundação Peirópolis, 2001.

FRUMKIN, P.; KIM, M.. Strategic Positioning and the Funding of Nonprofit Organizations: Is Efficiency Rewarded in the Contributions Marketplace?. Public Administration Review, v. 61, n. 3 mai./jun., 2001.

GORDON, T. P., KHUMAWALA, S. B.. The demand for nonprofit financial statements: A model for individual giving. Journal of Accounting Literature, v. 18, p. 31-56, 1999.

HAIR JR., Joseph F.; ANDERSON, Rojph E.; TATHAM, Ronald L.; BLACK, William C.. Multivatiate Data Analysis. $5^{\mathrm{a}}$ ed. Prentice-Hall, Inc., 1998.

MATIAS-PEREIRA, José. Curso de Gestão Estratégica na Administração Pública. São Paulo: Atlas, 2012.

MILANI FILHO, Marco A. F.. Avaliação de Desempenho de Organizações Filantrópicas: Uma Abordagem Quantitativa Baseada na Eficiência. Revista de Economia \& Relações Internacionais, v. 9, p. 101-120, 2011.

MILANI FILHO, Marco A. F.. A função controladoria em entidades filantrópicas: uma contribuição para a avaliação de desempenho. 2004. Dissertação (Mestrado). Curso de Pós-Graduação Controladoria e Contabilidade, Universidade de São Paulo - FEA/USP, São Paulo, (FEA/USP), 2004.

MORAES, Odair B. de; ABIKO, Alex K. Utilização da análise fatorial para a identificação de estruturas de interdependência de variáveis em estudos de avaliação pós-ocupação. In: 
Encontro Nacional de Tecnologia do Ambiente Construído, 11., 2006, Florianópolis/SC. Anais ...Florianópolis: ANTAC, 2006. CD-ROOM.

RIBEIRO, Lívia M. de P.; TIMÓTEO, Adriana C.. A Adoção dos Controles Internos em uma Organização do Terceiro Setor como Sustentabilidade Econômica: Um Estudo de Caso em uma Associação de Minas Gerais. Revista Contemporânea de Contabilidade, v. 9, n.17, p. 61-82, 2012.

TRUSSEL, John M.; PARSONS, Linda M.. Financial Reporting Factors Affecting Donations to Charitable Organizations. Advances in Accounting, v. 23, p. 263-285, 2008.

TRUSSEL, John M.; PARSONS, Linda M.. Financial Reporting Factors Affecting Donations to Charitable Not-for-Profit Organizations. American Accounting Association: MidAtlantic Region Meeting Paper, 2004. Disponível em: http://papers.ssrn.com/sol3/papers.cfm?abstract_id=481383. Acesso em: 12 março. 2012.

VALADÃO JUNIOR, Valdir M. de; MALAQUIAS, Rodrigo F.; SOUSA, Edileusa G. de. Controladoria como uma opção à sustentabilidade econômica nas organizações de Terceiro Setor: o caso de uma associação. Revista Contemporânea de Contabilidade, Ano 5, v. 1, n. 9, p. 131-151, 2008. 